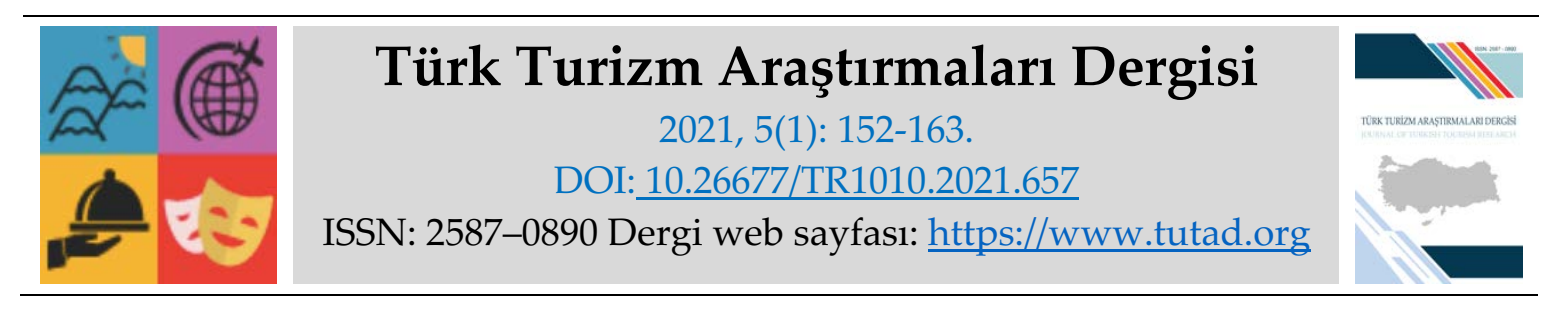

ARAȘTIRMA MAKALESI

\title{
Sağlık Turizmi Yetki Belgesi Bulunan Seyahat Acentelerinin Web Sitelerinin Değerlendirilmesi
}

Dr. Öğr. Üyesi Neşe ÇULLU KAYGISIZ, Aksaray Üniversitesi, Turizm Fakültesi, Aksaray, eposta: nesecullu@aksaray.edu.tr ORCID: https://orcid.org/0000-0003-2738-1205

$\ddot{O} z$

Günümüzde daha fazla gelir elde etme ve turizmi 12 aya yayma isteği gibi nedenlerle ülkelerin sağlık turizmini geliştirmeye çalıştıkları görülmektedir. Ülkemiz de sağlık turizminden daha fazla pay alabilmek için birçok yasal düzenlemeler yapmaktadır. Bunlardan biri de uluslararası sağlık turizmi yetki belgesi alma zorunluluğudur. 2017 yılında Uluslararası Sağlık Turizmi ve Turistin Sağlığı Hakkındaki Yönetmeliğe göre sağlık turizminde aracilık yapacak seyahat acenteleri faaliyetlerini sürdürebilmek için yetki belgesi almak zorundadır. Bu çalışmanın amacı sağlik turizmi yetki belgesi bulunan seyahat acentelerinin web sitelerini incelemektir. Bu kapsamda uluslararası sağlık turizmi yetki belgesi bulunan 89 seyahat acentesinin web sitesi içerik analizi yöntemiyle incelenmiştir. Araştırma sonucunda çoğu acente web sitesinde kurum bilgisi, hizmet bilgisi ve kolaylaştırıcı işlemlerin bulunduğunu ancak fiyat, paket fiyat gibi finansal bilgilerin bulunmadığı görülmüştür.

Anahtar Kelimeler: Sağlık Turizmi, Seyahat Acentesi, Web Sitesi.

Makale Gönderme Tarihi: 07.10.2020

Makale Kabul Tarihi: 03.03.2021

\section{Önerilen Atıf:}

Çullu Kaygisız, N. (2021). Sağlik Turizmi Yetki Belgesi Bulunan Seyahat Acentelerinin Web Sitelerinin Değerlendirilmesi, Türk Turizm Araştırmaları Dergisi, 5(1): 152-163.

(C) 2021 Türk Turizm Araştırmaları Dergisi. 


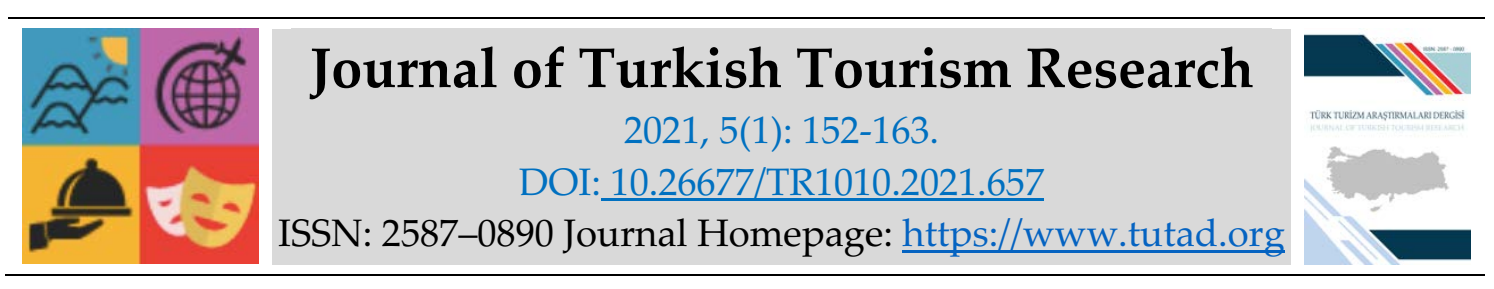

\title{
RESEARCH PAPER
}

\section{Evaluation of Web Sites of Travel Agencies with Health Tourism Authorization Certificate}

Assistant Prof. Dr. Neşe ÇULLU KAYGISIZ, Aksaray University, Faculty of Tourism, Aksaray, e-mail: nesecullu@aksaray.edu.tr

ORCID: https://orcid.org/0000-0003-2738-1205

\begin{abstract}
Today, we see that countries are trying to develop health tourism for reasons such as the desire to generate more income and spread tourism to 12 months. Our country also makes many legal regulations in order to get a higher share from health tourism. One of these is the requirement to obtain an international health tourism authorization certificate. In 2017, according to the Regulation on International Health Tourism and Tourist Health, travel agencies that will act as an intermediary in health tourism have to obtain a license to continue their activities. The purpose of this study is to examine the websites of travel agencies with health tourism authorization. In this context, the websites of 89 travel agencies with international health tourism authorization certificates were analyzed using content analysis method. As a result of the research, it was seen that most agency websites contain corporate information, service information and facilitating transactions, but not financial information such as price, package price.
\end{abstract}

Keywords: Health Tourism, Travel Agency, Website.

Received: 07.10.2020

Accepted: 03.03.2021

\section{Suggested Citation:}

Çullu Kaygisız, N. (2021). Evaluation of Web Sites of Travel Agencies with Health Tourism Authorization Certificate, Journal of Turkish Tourism Research, 5(1): 152-163.

(c) 2021 Türk Turizm Araştırmaları Dergisi. 


\section{GİRIŞ}

Sağlık turizmi bireylerin sağlık hizmeti almak için bulundukları yer dışına yaptıkları seyahati içermektedir. Günümüzde daha kaliteli hizmet almak, daha az maliyet, daha az bekleme süresi gibi birçok nedenden dolayı sağlık turizmine yönelim artmıştır. Dünya Turizm Örgütü' nün 2020 yılı verilerine göre 2019 yılında dünyada 1,5 milyar kişi turizm hareketine katılmıştır. Bu seyahatlerin \%27'si akraba ziyareti, din ve sağlık amacıyla yapılmıştır (UNWTO, 2020).

Yaşadıkları yer dışında farklı bir destinasyonda sağlık hizmeti almaya karar veren hastalar, tedavi öncesinde, tedavi esnasında ve tedavi sonrasında tıbbi olmayan bazı konularla ilgili hizmet almaya ihtiyaç duyarlar. Ülke dışında sağlık hizmeti almak için karar verme aşamasında olan hastalara güven verilmesi, korku ve tereddütlerinin giderilmesi oldukça önemlidir. Bu aşamada aracı kurumlara önemli görevler düşmektedir (SATURK). Seçim yapılabilecek birden fazla destinasyon olması ve sağlık turizmi seyahati için güvenilirliğin önemli olması sebebiyle, pek çok potansiyel sağlık turisti, yolculukları için seyahatlerini düzenleyecek bir aracı kuruma yönelmektedir (Cormany ve Baloğlu, 2011).

Sağlık turistleri seyahat formalitelerinden kurtulmak ve seyahat düzenlemelerini sorunsuz bir şekilde hazırlayabilmek için güvenilir acentelere ihtiyaç duymaktadırlar. Sağlık turizminde, bu aracılar, bir ülkedeki hasta adayları ile dünyanın diğer yerlerindeki tıbbi tesisler arasında etkileşime geçmede moderatör olarak önemli bir rol oynarlar (Mohamad, Omar ve Haron, 2012). Aracı kurum olan seyahat acenteleri seyahatin planlama aşamasından turistin eve dönüşüne kadar temas halinde olan işletme olduğu için sağlık turistleri için oldukça önemlidir.

İnternet seyahat bilgisi edinmede en önemli kaynaklardan biridir (Çubukçu, 2010). Özellikle sağlık turizminde bu durum daha da önem kazanmaktadır. Sağlık turistleri sağlık hizmeti alacağı destinasyonu seçmeden önce internetten araştırma yapmaktadır. Bu süreçte aracı kuruluş olan seyahat acentelerinin web siteleri önemli rol oynamaktadır.

Tedavi olacakları destinasyon hakkında bilgi sahibi olmak isteyen sağlık turistleri, dijital iletişimi kullanmaktadırlar (Öksüz ve Altıntaş, 2017). Web siteleri sağlık turizminde bir iletişim aracı olarak turistlere bilgi sağlama, kolaylık, fiyat kıyaslaması yapma, rezervasyon yapma gibi birçok avantaj sunmaktadır. Bu nedenle işletmeler artık web sitelerine çok dikkat ediyorlar ve bir web sitesine sahip olmanın onlara potansiyel müşterilere kolayca ulaşma fırsatı verdiğinin farkına varmış, doğru ve gerçeğe dayalı bilgiler vererek müşterilerin güvenini kazanmaktadırlar (Loncaric, Basan ve Jurkovic, 2013).

İnternet turistlere sağlık hizmetleri konusunda bilgi edinme, işletmelere ise sundukları hizmetlerin reklamını yapma firsatı vermektedir. Sağlık turistlerinin internetten sağladıkları bilginin seyahat kararlarında önemli bir rolü bulunmaktadır. Bu nedenle sağlık turizmi hizmeti veren kuruluşların resmi web sayfalarının anlaşılır olması ve potansiyel turistlerin muhtemel sorularına cevap verir nitelikte bilgileri bulundurmaları gerekmektedir. Web siteleri iletişimi kolaylaştırdığı için sağlık turizminde kullanılan önemli bir araçtır. Doğru bilgiler veren iyi hazırlanmış web siteleri sağlık turizmi tercihlerini etkileyebilir. Bu sebeple günümüzde sağlık kuruluşları web sitelerini güncelleştirip geliştirmek için çaba harcamaktadırlar (Çavuşgil Köse, Karalar ve Usta, 2018).

$\mathrm{Bu}$ çalışmanın amacı, sağlık turizminde aracılık hizmeti veren sağlık turizmi yetki belgesi bulunan seyahat acentelerinin web sitelerini içerik analizi kullanarak incelemektir. Çalışma kapsamında öncelikle ilgili literatür verilmiştir. İlgili literatürden sonra çalışmanın yöntem kısmı yer almaktadır. Daha sonra çalışmanın bulgularına yer verilmiş ve çalışma tartışma, sonuç bölümüyle tamamlanmıştır. 


\section{İLGILİ LITERATÜR}

İnternet ve iletişim araçlarının gelişmesiyle web siteleri işletmelerin sanal vitrini haline gelmiştir (Yalçın ve Bahar, 2019). Tüketiciler bir ürünü satın almak veya bilgiye ulaşmak amacıyla interneti kullanırlar. Bu nedenle işletmelerin sunmuş oldukları hizmetler hakkındaki bilgileri web sitelerinde özenli bir şekilde yer vermeleri oldukça önemli bir konudur (Bayram ve Yaylı, 2009).

Turizm işletmelerinin web sitelerini inceleyen birçok çalışma bulunmaktadır. Bu çalışmaların bazıları konaklama işletmelerinde, bazıları yiyecek içecek işletmelerinde bazıları ise seyahat işletmelerinde yapılmıştır.

Karamustafa, Biçkes ve Ulama (2002) konaklama işletmelerinin web sitelerini incelemişlerdir. Araştırma sonucunda işletme web sitelerinin genel olarak durağan olduğu sonucuna varmışlardır. Bayram ve Yaylı (2009) otel web sitelerini içerik analizi yöntemiyle değerlendirdikleri çalışmalarında otel web sitelerinin çoğunluğunun bilgi sağlayıcı özellikler taşıdığı sonucuna varmışlardır. Çubukçu (2010) Ege bölgesinde faaliyet gösteren konaklama işletmelerinin web site içeriklerini 20 ölçüt belirleyerek değerlendirmiştir. Değerlendirme sonucunda çoğu konaklama işletmesinin web sitelerinde bilgi sağlayıcı özellikler olduğu görülmüştür. Çiçek, Demirel ve Onat (2010) Burdur'da faaliyet gösteren işletmelerin web sitelerini içerik analizi yöntemi kullanarak incelemişlerdir. İnceleme sonucunda işletmelerin büyük çoğunluğunun web sitelerinin güncel olmadığı ve web sitelerini etkin bir şekilde kullanmadıkları sonucuna varılmıştır.

Seyahat acentelerinin web sitelerinin farklı gruplar tarafından değerlendirildiği bir çalışmada pazarlama, işlevsellik, etkileşim ve temel bilgiler açısından turistler ve uzmanlar arasında algı farkı olduğu bulunmuştur (Kokash, 2012). Erdoğan, Erdoğan ve Tosun (2012) seyahat acentelerinin web sitelerindeki çevresel içerik üzerine yaptıkları araştırma sonucunda, acentelerin büyük çoğunluğunun web sitesinde çevreyle ilgili hiçbir konunun yer almadığ görülmüştür. Dalgın ve Karadağ (2013) Muğla'da faaliyet gösteren restoran işletmelerinin web sitelerini incelemişlerdir. Araştırma sonucunda işletmelerin web sitelerini yeterince etkin kullanmadıkları görülmüştür. Doğan ve Kekeç Morkoç (2015) seyahat acentelerinin web sitelerini kullanma düzeyi hakkında yaptıkları araştırma sonucunda, acentelerin web sitelerini yeterince kullanmadıkları sonucuna varmışlardır.

Cesur ve Boz (2015) Çanakkale'de faaliyet gösteren A grubu seyahat acenteleri üzerinde yapmış oldukları çalışmada acente web sitesinin güncelliğinin satışların artışında önemli bir etken olduğu sonucuna varmışlardır. Ayrıca araştırmanın yürütüldüğü acente web sitelerinin çoğunda dil seçeneğinin bulunmadığı görülmektedir. Ateş ve Boz (2015) Çanakkale'de faaliyet gösteren 3, 4 ve 5 yıldızlı konaklama işletmelerinin web sitelerini değerlendiren bir çalışma yapmışlardır. Çalışmalarında turizm işletmeleri için bilgi teknolojilerinin önemli olduğu ve web sitelerinin bir pazarlama aracı olarak kullanılabileceğini vurgulamışlardır. Araştırma sonucunda konaklama işletmelerinin birçoğunun web sitesinin bulunduğu fakat etkili bir şekilde kullanamadıklarını ortaya koymuşlardır.

Cengiz ve Akkuş (2015) Erzurum ilinde faaliyet gösteren turizm işletmelerinin web sitelerini inceleyen çalışmaları sonucunda, web sitelerinin vasat bir görünüm sergilediği sonucuna varmışlardır. Pamukçu ve Arpacı (2016) yaptıkları çalışmada helal konseptli otel işletmelerinin web sitelerini incelemişlerdir. Araştırma sonucunda otel işletmelerinin web sitelerinde online rezervasyon, ulaşım haritası, otel özellikleri, odalarda sunulan hizmetler, otel fotoğrafları, restoranlar, iletişim bilgileri, yabancı dil desteği ve sosyal medya linki hizmetlerinin çoğunlukla verildiği ancak, helal otel sertifika bilgisi, helal yiyecek içecek gibi konularda çok az bilgi olduğu görülmüştür. 
Taş, Akkaşoğlu ve Akyol (2018) İstanbul'da faaliyet gösteren IATA üyesi A grubu seyahat acentelerinin web sitelerini incelemişlerdir. Araştırma sonucunda genel olarak acentelerin web sitelerini etkili ve verimli bir şekilde kullanmadıkları görülmüştür. Ünal ve Çelen (2018) turizm işletme belgesine sahip beş yıldızlı otel işletmelerinin web sitelerini değerlendirdikleri çalışmalarında, otel web sitelerinde genellikle iletişim ve konum bilgisine yer verildiğini tespit etmişlerdir. Yalçın ve Bahar (2019) A grubu seyahat acentelerinin web sitelerini betimsel analizle inceleyip aynı zamanda web sitelerini tüketici bakış açılarıyla değerlendirmişlerdir. Araştırma sonucunda web sitelerinin bilgilendirme amacıyla kullanıldığı ve tüketici beklentileri ile uyuşmadığı sonucuna varmışlardır.

Yukarıda verilen turizm işletmelerinde uygulanan çalışmalar dışında, sağlık turizmiyle ilgili kuruluşların web sitelerinin incelendiği çalışmalar da mevcuttur. Birdir ve Buzcu (2014) JCI akreditasyon belgesine sahip olan sağlık kuruluşlarının web sitelerini medikal turizm açısından değerlendiren bir çalışma yapmışlardır. Çalışmaları sonucunda sağlık kuruluşlarının çoğunun web sitesinde yabancı dil, hastane konumu, iletişim bilgisi, anlaşmalı kurumlar ve internet üzerinden randevu olanağı gibi bilgilerin bulunduğu ancak tedavi ücretleri konusunda bilgi verilmediği sonucunu bulmuşlardır.

Web siteleri potansiyel turistleri çekmek için kullanılan önemli bir araçtır. Sağlık turizminde aracı kuruluşların web sitelerinin incelendiği bir çalışmada web sitelerinin risklerden çok faydalardan bahsederek potansiyel müşterileri ikna ettikleri bulunmuştur (Lee vd., 2014). Constantin ve Kavoura (2016), sağlık turizminde web sitelerinin önemli bir iletişim aracı olarak kullanıldığını, web sitelerinin bilgilendirici işlevi bulunduğunu ve yabancı dil seçeneğinin bulunmasının uluslararası hastalar için önemli olduğunu belirtmektedir.

Web sitelerde bulunan bilgiler bölgelere göre değişiklik gösterebilmektedir. Yapılan bir çalışmada coğrafi bölgeye göre sağlık turizmi aracılarının web sitelerinde kültürden kaynaklanan bilgi farklılı̆̆ı bulunduğu ortaya çıkmıştır (Frederick ve Gan, 2015). Yapılan çalışmalar incelendiğinde web sitelerinin büyük çoğunluğunda iletişim ile ilgili bilgilerin bulunduğu görülmektedir. Maguire vd., (2016) tarafından yapılan çalışma incelendiğinde medikal turizm seyahat acentelerinin web sitelerinde iletişim formlarının bulunma oranı oldukça yüksekken, risk oranları ile ilgili bilgilerin bulunmadığı görülmektedir. Temizkan ve Konak (2018) medikal seyahat planlayıcılarının web sitelerini incelemişlerdir. Araştırma sonucunda seyahat planlayıcılarının web sitelerini etkin bir şekilde kullandıkları ve bir seyahat acentesi gibi hizmet verdikleri sonucuna ulaşmışlardır.

Sağlık turizmi geliştikçe bu konuda yapılan araştırmaların sayısı da artmaya başlamıştır. Sadece seyahat acenteleri üzerine değil aynı zamanda sağlık turizmi hizmeti veren hastaneler üzerine yapılan çalışmalar da mevcuttur. 2017 yılında Asya ülkelerinde bulunan sağlık turizmi hizmeti veren özel hastaneler üzerine yapılan bir çalışmada Hindistan, Malezya ve Tayland'da hizmet veren 51 özel hastanenin web sitesi hastane bilgileri, tıbbi hizmetler, etkileşimli çevrimiçi hizmetler, dış faaliyetler ve teknik unsurlar açısından incelenmiştir. Araştırma sonucunda hastanelerin web sitelerini geliştirmeleri gerektiği ortaya çıkmıştır (Moghavvemi vd., 2017).

\section{YÖNTEM}

$\mathrm{Bu}$ çalışmanın amacı, sağlık turizmi yetki belgesine sahip seyahat acentelerinin web sitelerinin içerik analizi yöntemiyle incelenmesidir. Sağlık turizminde aracı olan seyahat acenteleri hasta ile ilk buluşma noktasıdır. Potansiyel sağlık turistleri, tedavi amacıyla seyahat etmeden önce aracı kurumların web sitelerini kullanmaktadırlar. Bu nedenle sağllk turizmi yetki belgesi bulunan seyahat acentelerinin web sitelerinin incelenmesi önemli görülmektedir. 
Araştırmanın evrenini sağlık turizmi yetki belgesine sahip seyahat acenteleri oluşturmaktadır. 2017 yılında Resmi Gazete'de yayınlanan Uluslararası Sağlık Turizmi ve Turistin Sağlığı Hakkında Yönetmeliğe göre "uluslararası sağlık turizmi faaliyeti yürüten sağlık tesisi ve aracı kuruluşlar, yürürlük tarihinden itibaren 1 (bir) yıl içinde yetkinlik kriterlerine uygunluk sağlayarak Bakanlık'tan yetki belgesi almak zorundadır". 21.08.2020 tarihi itibariyle uluslararası sağlık turizmi yetki belgesine sahip 130 seyahat acentesi bulunmaktadır. Örnekleme yöntemine gidilmemiş ve tam sayım yapılarak 130 seyahat acentesi araştırmaya dahil edilmiştir. Bu acentelerin listesine Sağlık Bakanlığı'nın sitesinden ulaşılmıştır. Acentelerin isimleri arama motoruna girilerek web adreslerine ulaşılmaya çalışılmıştır. 130 seyahat acentesinden 89 acentenin web sitesine erişim sağlanmıştır.

Araştırmada acente web sitelerini incelemek için Temizkan ve Konak (2018) tarafından medikal seyahat planlayıcılarının web sitelerini incelemek için kullandıkları 7 boyut ve 43 ifadeden oluşan değerlendirme formundan yararlanılmıştır. Form seyahat acentelerine uyarlanarak bazı ifadeler çıkarılmış ve 6 boyut ve 30 ifadeden oluşan form kullanılmıştır.

Değerlendirme formuna göre incelenen web siteleri bilgisayar ortamına aktarılarak 1 Evet 2 Hayır şeklinde kodlanmıştır. Verilerin analizinde frekans ve yüzde analizi kullanılmıştır.

\section{BULGULAR}

Acente web siteleri kurum bilgileri, paydaş bilgileri, hizmet bilgileri, güncellik ve bilgilendirme, kolaylaştırıcı işlemler ve finansal bilgiler olmak üzere 6 boyutta incelenmiştir. Elde edilen verilere frekans ve yüzde analizleri yapılmıştır. Değerlendirme formuna göre incelenen 89 seyahat acentesinin web sitesine ait kurum bilgilerine Tablo 1'de yer verilmiştir.

Tablo 1: Kurum Bilgilerine İlişkin Bulgular

\begin{tabular}{lcc}
\hline Kurum Bilgileri & $\mathbf{f}$ & $\mathbf{\%}$ \\
\hline Tarihçe & 71 & 79,8 \\
\hline Telefon numarasi & 89 & 100 \\
\hline Adres bilgisi & 89 & 100 \\
\hline Harita & 66 & 74,2 \\
\hline Misyon/vizyon ifadeleri & 64 & 71,9 \\
\hline Logo sembolü & 78 & 87,6 \\
\hline Ziyaretçi bilgisi & 9 & 10,1 \\
\hline
\end{tabular}

Seyahat acentelerinin web sitelerinde kurum bilgilerine bakıldığında, kurumun tarihçesinin 71 acentenin web sitesinde olduğu, telefon numarası ve adres bilgilerinin ise bütün web sitelerinde olduğu görülmektedir. İşletmelerin konumunu gösteren harita bilgisinin 66 acente web sitesinde, kurumun amacının gösteren vizyon ve misyon bilgilerinin 64 acentede, kurumun sembolü olan logonun 78 acentede, web sitesine giren ziyaretçi sayısının ise sadece 9 acente web sitesinde olduğu görülmektedir. Genel olarak kurum bilgileri değerlendirildiğinde acentelerin çoğunun web sitesinde bu bilgilerin bulunduğu söylenebilir.

Paydaş bilgilerinin verildiği Tablo 2 incelendiğinde en yüksek hasta hakları hakkında bilginin olduğu görülmektedir. 89 acentenin 19'unda kurum hekimleri hakkında bilgiler bulunurken 15 acentenin web sitesinde ise hasta memnuniyet bilgisi olduğu görülmektedir. En az bilgi ise hastaya özel linkler ile ilgilidir. 89 acente içinden sadece 6 acentede hastaya özel linkler 
sunulmuştur. Paydaş bilgilerine ilişkin bulgular genel olarak değerlendirildiğinde çoğu acente web sitelerinde bu bilgilerin bulunmadı ̆̆ı görülmektedir.

Tablo 2: Paydaş Bilgilerine İlişkin Bulgular

\begin{tabular}{lcc}
\hline Paydaş Bilgisi & f & $\mathbf{\%}$ \\
\hline Hastaya özel linkler & 6 & 6,7 \\
\hline Kurum hekimleri bilgisi & 19 & 21,3 \\
\hline Hasta hakları & 25 & 28,1 \\
\hline Hasta memnuniyeti bilgisi & 15 & 16,9 \\
\hline
\end{tabular}

Tablo 3: Hizmet Bilgilerine İlişkin Bulgular

\begin{tabular}{lcc}
\hline Hizmet Bilgisi & f & \% \\
\hline Hizmet Bilgisi & 83 & 93,3 \\
\hline Akreditasyon bilgisi (JCI) & 24 & 27 \\
\hline
\end{tabular}

Hizmet bilgilerine ilişkin bulgular incelendiğinde acentelerin büyük çoğunluğunun $(\% 93,3)$ web sitesinde hizmet bilgisinin bulunduğu görülmektedir. Seyahat acentelerinin anlaşmalı olduğu sağlık kurumlarının akreditasyon bilgisi 24 acentenin web sitesinde bulunmaktadır. Sağlık hizmetlerinin kalitesinin güvencesi olan akreditasyon bilgisinin acente web sitelerinde bulunması potansiyel sağlık turistlerinin karar vermelerini kolaylaştıracaktır. Bu nedenle acentelerin web sitelerinde bu bilgilerin paylaşılmasına önem vermeleri gerekmektedir.

Tablo 4: Güncellik ve Bilgilendirme ile İlgili Bulgular

\begin{tabular}{lcc}
\hline Güncellik ve Bilgilendirme & $\mathrm{f}$ & $\%$ \\
\hline Telif hakkı (copyright) tarihi & 72 & 80,9 \\
\hline Son güncelleme tarihi & 16 & 18 \\
\hline Gizlilik ilkeleri ve kullanım şartları & 39 & 43,8 \\
\hline
\end{tabular}

Tablo 4 incelendiğinde telif hakkı tarihinin 72 acentenin web sitesinde bulunduğu görülmektedir. Gizlilik ilkeleri ve kullanım şartları 39 acentenin web sitesinde mevcutken, son güncelleme tarihi ise 16 acentede bulunmaktadır. Güncellik ve bilgilendirme ile ilgili bulgular genel olarak incelendiğinde acentelerin web sitelerinde bu bilgilere daha fazla yer vermeleri gerektiği söylenebilir.

Tablo 5: Kolaylaştırıcı İşlemler ile İlgili Bulgular

\begin{tabular}{lcc}
\hline Kolaylaştırıcı İşlemler & f & $\mathbf{\%}$ \\
\hline Site içi arama & 51 & 57,3 \\
\hline Dil seçeneği & 79 & 88,8 \\
\hline Randevu işlemleri & 46 & 51,7 \\
\hline E-randevu & 40 & 44,9 \\
\hline Sık sorulan sorular & 21 & 23,6 \\
\hline Canlı yardım & 28 & 31,5 \\
\hline Pasaport/vize yardımı & 39 & 43,8 \\
\hline
\end{tabular}


Kolaylaştırıcı işlemler açısından web sitelerine bakıldığında dil seçeneği dikkat çekmektedir. 89 acentenin 79'unda dil seçeneği bulunmaktadır. 79 acentenin web sitesinde İngilizce dil seçeneği mevcuttur. İngilizcenin yanında Almanca, Arapça ve Rusça en çok bulunan diller arasındadır. Kolaylaştırıcı işlemlerden site içi arama 51 acentenin web sitesinde mevcuttur. 46 acentede randevu işlemleri, 40 acentede e-randevu, 39 acentede pasaport/vize yardımı, 28 acentede canlı yardım ve 21 acentede sık sorulan sorular bulunmaktadır.

Tablo 6: Finansal Bilgiler ile İlgili Bulgular

\begin{tabular}{lcc}
\hline Finansal Bilgiler & f & $\mathbf{\%}$ \\
\hline Fiyatlar & 9 & 10,1 \\
\hline Paket fiyatlar & 3 & 3,4 \\
\hline Anlaşmalı hastaneler & 52 & 58,4 \\
\hline Hastane içi konaklama & 31 & 34,8 \\
\hline Otelde konaklama & 41 & 46,1 \\
\hline Ödeme seçenekleri & 9 & 10,1 \\
\hline Sigorta seçenekleri & 7 & 7,9 \\
\hline
\end{tabular}

Tablo 6' da verilen finansal bilgilerle ile ilgili bulgular incelendiğinde 52 acentenin web sitesinde anlaşmalı kurumlarla ilgili bilgilerin bulunduğu görülmektedir. 41 acentede otelde konaklama, 31 acentede hastane içi konaklama, 9 acentede fiyatlar ve ödeme seçenekleri, 7 acentede sigorta, 3 acentede ise paket fiyatlar hakkında bilgiler mevcuttur. Acente web sitelerinde bulunan finansal bilgilere ait bulgular genel olarak değerlendirildiğinde bu bilgilerin web sitelerinde yar alması hakkında bir eksiklik olduğu söylenebilir.

Tablo 7: Acente Web Siteleri ile İlgili Genel Bulgular

\begin{tabular}{lcc}
\hline Boyutlar & f & $\mathbf{\%}$ \\
\hline Kurum Bilgileri & 82 & 82,1 \\
\hline Paydaş Bilgileri & 12 & 13,5 \\
\hline Hizmet Bilgileri & 24 & 27 \\
\hline Güncellik ve Bilgilendirme & 42 & 47,2 \\
\hline Kolaylaştırıcı İşlemler & 41 & 46,1 \\
\hline Finansal Bilgiler & 10 & 11,2 \\
\hline
\end{tabular}

Acente web sitelerine ilişkin genel bulgular incelendiğinde en fazla bilginin kurum bilgileri hakkında olduğu görülmektedir. Kurum bilgilerinden sonra güncellik ve bilgilendirme ve kolaylaştırıcı işlemler hakkındaki bilgilerin acente web sitelerinde yer aldığı görülmektedir. Hizmet bilgileri, paydaş bilgileri ve finansal bilgilerin ise acente web sitelerinde daha az yer aldığı söylenebilir.

\section{TARTIŞMA, SONUÇ ve ÖNERİLER}

Uluslararası sağlık turizmi yetki belgesi bulunan seyahat acentelerinin web sitelerinin incelendiği bu çalı̧̧mada acenteler, kurum bilgileri, paydaş bilgileri, hizmet bilgileri, güncellik ve bilgilendirme, kolaylaştırıcı işlemler ve finansal bilgiler olmak üzere 6 boyutta incelenmişlerdir. 
Kurum bilgileri boyutu 7 maddeden, paydaş bilgisi boyutu 4 maddeden, hizmet bilgileri 2 maddeden, güncellik ve bilgilendirme 3 maddeden, kolaylaştırıcı işlemler 7 maddeden ve finansal bilgiler 7 maddeden oluşmaktadır.

Araştırma bulguları incelendiğinde, kurum bilgisi boyutunda bulunan ziyaretçi bilgisi hariç diğer 6 bilginin acentelerin büyük çoğunluğunda bulunduğu söylenebilir. Özellikle telefon numarası ve adres bilgilerinin bütün acentelerin web sitesinde bulunduğu görülmektedir. Bu sonuçlar dikkate alındığında araştırma kapsamında incelenen acentelerin kurum bilgilerini web sitelerinde paylaşmayı önemsediklerini ve müşterilerin acenteye ulaşmak için telefon numaralarını kullanacaklarını öngördükleri söylenebilir. Bu araştırma sonucu literatürdeki diğer araştırmalar tarafından da desteklenmektedir. Örneğin, Maguire vd., (2016) medikal turizm seyahat acentelerinin web sitelerini inceledikleri çalışmalarında Avrupa'da bulunan acente web sitelerinde iletişim bilgilerinin bulunduğu sonucuna varmışlardır.

Araştırma kapsamında bir diğer boyut olan paydaş bilgisi bulguları incelendiğinde bu bilgilerin web sitelerinde bulunma oranının düşük olduğu söylenebilir. Bu boyut kapsamında hastaya özel linkler, hekim bilgileri, hasta hakları ve hasta memnuniyet bilgileri bulunmaktadır. Bu bilgilerin özellikle yurt dışından gelecek olan hastalar için önemli olduğu söylenebilir. Özellikle kurum hekim bilgisinin ve müşteri memnuniyet bilgisinin web sitesinde bulunması hastaların hem karar vermelerini kolaylaştıracağı hem de hastalara güven sağlayacağından bu bilgilerin web sitelerine eklenmesi önerilmektedir.

Hizmet bilgisi boyutu incelendiğinde acentelerin \%93,3'ünün sunmuş olduğu hizmet bilgilerini web sitelerinde paylaştıkları görülmektedir. Bu bilginin varlığı, web sitesini inceleyen potansiyel sağlık turistlerinin karar vermesini kolaylaştıracaktır. Bu boyutta yer alan akreditasyon bilgisi ise acentelerin \%27' sinde bulunmaktadır. Akreditasyon bilgisinin varlığı sağlık turistlerinin kuruma olan güvenini etkilemektedir. Bu nedenle bu bilgilerin web sitesinde bulunması önemli görülmektedir.

Güncellik ve bilgilendirme boyutunda telif hakkı tarihi, son güncelleme tarihi, gizlilik ilkeleri ve kullanım şartları ifadeleri bulunmaktadır. Yaklaşık \%81 acentenin web sitesinde telif hakkı tarihi bulunmaktadır. \%18 acentede son güncelleme tarihi ve yaklaşı $\% 44$ acentede ise gizlilik ilkeleri ve kullanım şartları bulunmaktadır. Araştırma kapsamındaki acenteler sağlık hizmetine aracılık yapan acenteler olduğu için güncellik ve bilgilendirmenin web sitelerinde bulunması oldukça önemlidir.

Kolaylaştırıcı işlemler; site içi arama, dil seçeneği, randevu işlemleri, e-randevu, sık sorulan sorular, canlı yardım ve pasaport/vize yardımı ifadelerinden oluşmaktadır. Dil seçeneği yaklaşık $\% 90$ acentenin web sitesinde bulunmaktadır. Bu seçeneğin olması özellikle yurt dışından gelecek sağlık turistleri açısından oldukça önemlidir. İngilizce, Almanca, Arapça ve Rusça en çok bulunan dil seçenekleri arasındadır. Diğer kolaylaştırıcı işlemlere bakıldığında bu işlemlerin acentelerin yaklaşık \%50'sinde bulunduğu söylenebilir. Bu işlemlerin bulunması potansiyel sağlık turistlerinin işlerini kolaylaştıracağı için karar vermelerinde yardımcı olacaktır. Constantin ve Kavoura (2016), tarafından yapılan çalışmada da sağlık turizmi ile ilgili kuruluşların web sitelerinde yabancı dil seçeneğinin bulunmasının uluslararası hastalar için önemli olduğu belirtilmektedir.

Finansal bilgiler boyutu; fiyatlar, paket fiyatlar, anlaşmalı hastaneler, hastane içi konaklama, otelde konaklama, ödeme seçenekleri ve sigorta seçenekleri olmak üzere 7 ifadeden oluşmaktadır. Anlaşmalı hastanelere ait bilgiler acentelerin yaklaşık \%60'ında, otelde konaklama bilgileri ise acentelerin yaklaşık \%50'sinde bulunmaktadır. Acentelerin web sitelerinde anlaşmalı hastanelerin bilgilerinin bulunması sağlık turistlerinin sağlık hizmetini hangi hastanelerden alacağını bilmesi açısından önemlidir. Aynı şekilde tedavi sonrasında hangi otelde konaklama 
yapılacağını bilmek sağlık turistlerini rahatlatacaktır. Bu boyutta yer alan bir diğer önemli bilgi fiyat bilgisidir. Sağlık turizminin yaygınlaşmasında önemli olan durumlardan biri daha ucuz sağlık hizmeti almaktır. Bu nedenle aracı kuruluşların web sitelerinde fiyat ve paket fiyat bilgilerinin yer alması oldukça önemlidir. Fakat araştırma bulguları incelendiğinde acentelerin sadece $\% 10,1^{\prime}$ inde fiyat bilgisi, \%3,4'ünde ise paket fiyat bilgisi olduğu görülmektedir. Birdir ve Buzcu (2014) tarafından yapılan çalışmada da sağlık turizmi hizmeti veren kuruluşların web sitesinde fiyatlarla ilgili bilgilerin bulunmadığı ortaya çıkmıştır. Bu açıdan bu araştırma sonucu literatürü desteklemektedir.

Çalışma sonucunda 130 uluslararası sağlık turizmi yetki belgesine sahip seyahat acentesinden 41 acenteye ulaşım sağlanamadığını, ulaşılan 89 acentenin ise özellikle finansal ve paydaş bilgileri konularında web sitelerinde bilgi olmadığı görülmektedir. Genel olarak bütün boyutlar incelendiğinde ise çoğunlukla acentelerin bilgilendirme amaçlı web sitelerini kullandıkları söylenebilir. Bu durumu alan yazındaki diğer araştırma sonuçları da desteklemektedir. Bayram ve Yaylı (2009), Çubukçu (2010), Birdir ve Buzcu (2014) ,Constantin ve Kavoura (2016), Yalçın ve Bahar (2019) yapmış oldukları çalışmalarda web sitelerinin bilgi amaçlı kullanıldığı sonucuna varmışlardır.

Araştırma sonucunda bazı seyahat acentelerinin web sitelerini etkili bir şekilde kullanarak, hem kurum bilgileri, hem hekim hem de finansal bilgileri web sitelerinde sunduklarını aynı zamanda siteye girenlerin işlemlerini kolaylaştıracak fonksiyonların bulunduğu görülmektedir. Bazı acenteler ise web sitelerini sadece bilgilendirme amacıyla kullanmaktadır. Özellikle sağlık turizmine aracılık eden acenteler web sitelerinde potansiyel sağlık turistlerinin aklındaki sorulara cevap verecek bütün bilgileri paylaşmalı ve ödeme seçeneği, sigorta, pasaport/vize gibi konularda web sitesi üzerinden yardımcı olmalıdır.

Araştırma sonuçları incelendiğinde genel olarak, kurum bilgileri, hizmet bilgileri ve kolaylaştırıcı işlemlerin çoğu acentenin web sitesinde bulunduğu görülmektedir. Araştırma kapsamında ulaşılan 89 acentenin 51'i sadece sağlık turizmi kapsamında faaliyet gösteren acentelerdir. Diğer 38 acente ise sağlık turizmi yanında farklı turizm türlerinde de faaliyet göstermektedir. Daha sonra yapılacak çalışmalarda bu acenteler arasında kıyaslama yapılabilir.

\section{KAYNAKÇA}

Ateş, U. ve Boz, M. (2015). Konaklama İşletmelerinin Web Sitelerinin Değerlendirilmesi: Çanakkale Örneği, JEBPIR, 1 (1), 63-84.

Bayram, M. ve Yaylı, A. (2009). Otel Web Sitelerinin İçerik Analizi Yöntemiyle Değerlendirilmesi, Elektronik Sosyal Bilimler Dergisi, 8(27): 347-379.

Birdir, K. ve Buzcu, Z. (2014). JCI Akreditasyon Belgesine Sahip Olan Sağlık Kuruluşlarının WEB Sitelerinin Medikal Turizm Açısından Değerlendirilmesi, Çă̆ Üniversitesi Sosyal Bilimler Dergisi, 11(1): 1-19.

Cengiz, G. ve Akkuş, Ç. (2015). Erzurum İli Turizm İşletmeleri Web Kullanımı ve Web Sitelerinin Değerlendirilmesi, İktisadi ve İdari Bilimler Dergisi, 29 (3): 441-457.

Cesur, M. ve Boz, M. (2015). İnternetin Öneminin ve Kullanımının Seyahat Acentaları Perspektifinden Değerlendirilmesi: Çanakkale Örneği, Girişimcilik ve Kalkınma Dergisi, 10(1): 119146.

Constantin, F. and Kavoura, A. (2016). Multilingual Online Communications in Corporate Websites: Cases of Romanian Dental Practices and Their Application to Health Tourism, (Editör) 
Katsoni, V. and Stratigea, A.: Tourism and Culture in the Age of Innovation içinde (185-196) Switzerland: Springer International Publishing.

Cormany, D. and Baloglu, S. (2011). Medical travel facilitator websites: An exploratory study of web page contents and services offered to the prospective medical tourist, Tourism Management 32: 709-716.

Çavuşgil Köse, B., Karalar, S. ve Usta, I. (2018). Sağlık Turizmine Yetkili Kuruluşların Web Sitelerinin Kalite Yönetimi ve Turizm Perspektifinde Değerlendirilmesi, 19. Ulusal Turizm Kongresi, Afyonkarahisar.

Çiçek, H., Demirel, M. ve Onat, O. K. (2010). İşletmelerin Web Sitelerinin Değerlendirilmesine İlişkin Bir Araştırma: Burdur İli Örneği, Süleyman Demirel Üniversitesi İktisadi ve İdari Bilimler Fakültesi Dergisi, 15(2): 187-206.

Çubukçu, M. İ. (2010). Konaklama İşletmeleri Web Site İçeriklerinin Değerlendirilmesi, IUYD, 1 : 39-59.

Dalgın, T. ve Karadă̆, L. (2013). Restoran İşletmeleri Web Sitelerinin İçerik Analizi: MarmarisBodrum Örneği, AïBÜ Sosyal Bilimler Enstitüsü Dergisi, 13(2):133-150.

Doğan, M. ve Kekeç Morkoç, D. (2015). Seyahat Acentalarının Web Sitelerini Kullanma Düzeyi: “Çanakkale 2015" Teması Üzerinden Karşılaştırmalı Bir Analiz, Batman Üniversitesi Yaşam Bilimleri Dergisi, 5(2): 99-115.

Erdoğan, N. Erdoğan, İ. ve Tosun, C. (2012). Seyahat Acentelerinin Web Sitelerindeki Çevresel İçerik Üzerine Bir İnceleme, Sosyal ve Beşeri Bilimler Dergisi, 4(2): 223-233.

Frederick, J. R. and Gan, L. L. (2015). East-West differences among medical tourism facilitators' websites, Journal of Destination Marketing \& Management, 4: 98-109.

Karamustafa, K. Biçkes, D.M. ve Ulama, Ş. (2002). Türkiye'deki Konaklama İşletmelerinin İnternet Web Sitelerini Değerlendirmeye Yönelik Bir Çalışma, Erciyes Üniversitesi İktisadi ve İdari Bilimler Fakültesi Dergisi, 19:51-92.

Kokash, H. A. (2012). Jordanian Travel Agencies' Websites Assessment: Experts vs Tourists' Perceptions, International Journal of Marketing Studies, 4 (2): 80-92.

Lee, H., Wright, K. B., O'Connor, M. and Wombacher, K. (2014). Framing Medical Tourism: An Analysis of Persuasive Appeals, Risks and Benefits, and New Media Features of Medical Tourism Broker Websites, Health Communication, 29 (7): 637-645.

Loncaric, D., Basan, L. and Jurkovic, M. (2013). Website as a Tool of Promotion of Health Tourism Offering in Croatian Specialty Hospitals and Health Resorts, 1st International Conference on Management, Marketing, Tourism, Retail, Finance and Computer Applications, Dubrovnik.

Maguire, A., Bussmann, S., Köcker, C.M., Verra, S. E., Giurgi, L. A. and Ruggeri, K. (2016). Raising concern about the information provided on medical travel agency websites: A place for policy, Health Policy and Technology, 5: 414-422.

Moghavvemi, S., Ormond, M., Musa, G., Isa, C. R. M., Thirumoorthi, T., Mustapha, M.Z.M., Kanapathy, K. A. P. and Chandy, J.J.C. (2017). Connecting with prospective medical tourists online: A cross-sectional analysis of private hospital websites promoting medical tourism in India, Malaysia and Thailand, Tourism Management, 58: 154-163.

Mohamad, W.N., Omar, A. and Haron, M.S. (2012). The Moderating Effect of Medical Travel Facilitators in Medical Tourism, Procedia - Social and Behavioral Sciences, 65: 358 - 363. 
Öksüz, B. ve Altıntaş, V. (2017). Sağlık Turizminde Dijital İletişim Kanallarının Kullanımı, Seyahat ve Otel İşletmeciliği Dergisi, 14 (1): 59-75.

Pamukçu, H. ve Arpacı, Ö. (2016). Helal Konseptli Otel İşletmelerinin Web Sitelerinin Analizi, Çatalhöyük Uluslararası Turizm ve Sosyal Araştırmalar Dergisi, 1: 147-160.

SATURK, http://www.saturk.gov.tr/images/pdf/tyst/08.pdf. Erişim Tarihi 21.09.2020.

Taş, M. Akkaşoğlu, S. ve Akyol, C. (2018). Turizm İşletmelerinde Bilgi Teknolojileri Kullanımı Kapsamında Seyahat Acentesi Web Sitelerinin İncelenmesi, Akademik Bakış Dergisi, 66: 207-221.

Temizkan, S. P. ve Konak, S. (2018). Medikal Turizmde Medikal Seyahat Planlayıcılarının Web Siteleri Üzerine Bir Analiz, Journal of Gastronomy Hospitality and Travel, 1(2): 26-36.

UNWTO (2020) https://www.unwto.org/world-tourism-barometer-n18-january-2020 Erişim Tarihi 21.10.2020.

Ünal, A. ve Çelen, O. (2018). Türkiye'deki Otel İşletmelerinin Web Sitelerinin Değerlendirilmesine Yönelik Nitel Bir Araştırma, Balıkesir Üniversitesi Sosyal Bilimler Enstitüsü Dergisi, 21(40): 607-636.

Yalçın, M. ve Bahar, O. (2019). Seyahat Acentelerinin Web Sitelerinin Betimsel Analizi ve Tüketici Değerlendirmesi. OPUS-Uluslararası Toplum Araştırmaları Dergisi, 11(18): 286-320. 